E3S Web of Conferences 1, 13001 (2013)

DOI: $10.1051 / \mathrm{e} 3$ sconf/20130113001

(c) Owned by the authors, published by EDP Sciences, 2013

\title{
A time-series phytoremediation experiment with sunflowers (Helianthus annuus) on a former uranium mining site
}

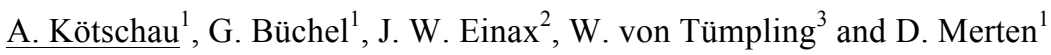 \\ ${ }^{1}$ Institute of Geosciences, Friedrich Schiller University of Jena, Burgweg 11, 07749 Jena, GERMANY, \\ anika.koetschau@uni-jena.de \\ ${ }^{2}$ Institute of Inorganic and Analytical Chemistry, Friedrich Schiller University of Jena, Lessingstraße 8, D-07743 Jena, \\ GERMANY \\ ${ }^{3}$ Helmholtz Centre for Environmental Research, Brückstraße 3a, 39114 Magdeburg, GERMANY
}

\begin{abstract}
On a test field situated at a former uranium mining site near Ronneburg (Thuringia, Germany) a small scale time-series field experiment with sunflowers (Helianthus annuus) was carried out. This area ghas elevated contents for the heavy metals $\mathrm{Cd}, \mathrm{Co}, \mathrm{Cr}, \mathrm{Cu}, \mathrm{Ni}, \mathrm{Zn}$ including the radionuclides $\mathrm{U}$ and $\mathrm{Th}$. Over a time period of 24 weeks the sunflowers were cultivated on homogenized soil substrate and regularly harvested. The aim was to find the ideal moment to harvest the sunflowers, being defined as having the best balance between the extraction of the contaminants and a high biomass produced. The contents of the elements were determined in soil, roots and above-ground plant parts. The contents in the above-ground plant showed no clear increasing or decreasing trend over time, so they were not the appropriate values to determine the best moment to harvest. Instead the total extracted masses (content in $\mu \mathrm{g} / \mathrm{g}$ x biomass in $\mathrm{g}$ ) of the contaminants in the above-ground plant parts were calculated. According to this the best moment to harvest the sunflower plants was reached after 24 weeks of vegetation, because the highest extracted masses for all contaminants were calculated to this time. Additionally the biomass, which could be used e.g. for bio-fuel production, was highest at this time.
\end{abstract}

Key words: Heavy metals, time-series experiment, sunflower, phytoremediation

\section{Introduction}

About $0.5 \%$ of the area in Europe are contaminated by mining activities, whereby mining waste amounts to about $30 \%$ of waste produced in Europe (Piirto, 2010). Mined areas are often characterized by contamination with heavy metals, acidic soil $\mathrm{pH}$, and low nutrient content. The classical methods used to remediate such areas are excavation and land-filling or washing with chemical solvents. So either huge amounts of soil have to be moved and suitable storage areas have to be found or much solvent has to be applied, which damages the soil and decreases its fertility (Singh and Prasad, 2011). Due to these negative impacts new in-situ decontamination methods should be investigated. Phytoremediation is a promising method to remove contaminants from soil in an eco-friendly and soft way. In addition it enhances the soil functionality and protects it from erosion. One further advantage is that these areas, which are not suitable for food crops can be used to grow plants for the bio-fuel production. In the area around Ronneburg (Thuringia, Germany) from 1946-1990 low grade uranium ores were mined and leached. Altogether about $113,000 \mathrm{t}$ of $\mathrm{U}$ were produced over the time. After 1990 the site was remediated by removing and filling the leached ores in open pit mines. New soil was applied and the landscape reconturized. The sealing of the former leaching heap was leaky, so heavy metal and radionuclide containing acid mine drainage could seep in the underlying basement. As a consequence the newly applied soil was again contaminated due to capillary rising. Nowadays the soil shows elevated contents for the heavy metals $\mathrm{Cd}, \mathrm{Co}, \mathrm{Cr}, \mathrm{Cu}, \mathrm{Ni}$, and $\mathrm{Zn}$ and the radionuclides $U$ and $T h$. On the area of the former leaching heap the test field "Gessenwiese" $\left(2500 \mathrm{~m}^{2}\right)$ was installed in 2004 (Grawunder et al., 2009). On a subplot $\left(9 \mathrm{~m}^{2}\right)$ at the test site filled with homogenized soil substrate, sunflowers were tested for their phytoextraction potential. Thereby one main question rised: When is the ideal moment to harvest the plants? Does it make sense to sow twice times a year, since over a vegetation period of e. g. three month the maximum extraction is reached and after that time only more biomass is formed? Is there only a "dilution" by biomass 
production after an initial uptake? Or does it make sense to grow plants over 6 months since they form more biomass and in addition accumulate more contaminants? Although this problem is very obvious and important to answer, no hints can be found in literature. Often the harvesting time is selected randomly and no explanation why the harvest is done at a certain time can be found (Madejón et al., 2003; Marchiol et al., 2007; Sabudak et al., 2007)

\section{Materials and Methods}

The study area is situated in middle-east of Germany near Ronneburg. As a result of former uranium mining activities the soil shows elevated contents for many heavy metals and radionuclides. The contents of the investigated elements $\mathrm{Cd}, \mathrm{Co}, \mathrm{Cr}, \mathrm{Cu}, \mathrm{Ni}, \mathrm{Zn}, \mathrm{U}$, and $\mathrm{Th}$ in the homogenized soil substrate on which the sunflowers were planted can be found in Tab. 1. These total contents of the contaminants in the sandy loam soil were determined with ICP-MS after digestion with HF (suprapur, $40 \%$ ), $\mathrm{HClO}_{4}$ (suprapur, $70 \%$ ), and $\mathrm{HNO}_{3}$ (subboiled, $65 \%$ ) in a PicoTrace (DAS 30) apparatus. The soil has a $\mathrm{pH}$ about 4.6-5.0 $\left(\mathrm{H}_{2} \mathrm{O}\right)$ and an organic carbon content $<0.1 \%$.

Tab. 1 Total element concentrations in soil \pm confidence interval

\begin{tabular}{cc}
\hline Element & $\begin{array}{c}\text { Concentration in } \\
\mu \mathrm{g} / \mathrm{g}\end{array}$ \\
\hline $\mathrm{Cd}$ & $0.72 \pm 0.04$ \\
\hline $\mathrm{Co}$ & $26.2 \pm 0.1$ \\
\hline $\mathrm{Cr}$ & $45.8 \pm 0.6$ \\
\hline $\mathrm{Cu}$ & $29.8 \pm 0.3$ \\
\hline $\mathrm{Ni}$ & $54.8 \pm 0.6$ \\
\hline $\mathrm{Zn}$ & $74.8 \pm 0.4$ \\
\hline $\mathrm{Th}$ & $10.1 \pm 0.1$ \\
\hline $\mathrm{U}$ & $4.68 \pm 0.1$ \\
\hline
\end{tabular}

We selected sunflower (Helianthus annuus), based on preliminary experiments in this area which showed that they germinate and grow well on the contaminated, acidic soil substrate. We grew them over 24 weeks, which equals a normal vegetation period in agricultural use. During this time we took samples at least every five weeks samples. The plants were seperated in above-ground parts and roots, three times washed washed with deionzeid water and dried at $40^{\circ} \mathrm{C}$ to weight constance. Following they were ground (RETSCH, MM400) and digested with $\mathrm{HNO}_{3}$, (subboiled, $65 \%$ ) in a microwave oven (CEM, MARSXPRESS). The concentrations of the elements in the digests were determined by ICP-MS (X-Series II, ThermoFisher Scientific).

\section{Results and Discussion}

After 24 weeks of vegetation no toxicity symptoms were visible on the sunflowers. The experiment was finished after this time, because the sunflowers withered.
Focusing on the variation of the contents in the above-ground plant parts an ideal moment to harvest the sunflowers, that would be indicated by highest contents for all elements at a certain time, could not be determined. Over this time no clear decreasing or increasing trend for all elements is visible (Fig. 1). Cd, $\mathrm{Cr}$ and $\mathrm{Zn}$, reach the highest content already after 5 weeks of vegetation, whereas the contents of $\mathrm{Co}, \mathrm{Cu}$, and $\mathrm{Ni}$ are highest after 20 week. $U$ and Th have the highest values after 15 weeks of growth and are lower before and after this time. The biomass was about $0.7 \mathrm{~g}$ after five weeks, $2.1 \mathrm{~g}$ after 15 weeks increasing to $5 \mathrm{~g}$ dry weight per plant after 24 weeks of growth. Because of this contrasting behavior we calculated the total extracted mass of the elements (content in $\mu \mathrm{g} / \mathrm{g} \times$ biomass in $\mathrm{g}$ ). The results (Fig. 2) indicate that the maximum extracted mass for all elements is reached at the $24^{\text {th }}$ week of the vegetation period. At this time the extracted mass e.g. for $\mathrm{Cu}$ is about ten times higher than after five weeks and two times higher compared to 15 weeks of vegetation. An exception are $T h$ and $U$, both reach their highest extraction already after 18 weeks. The sunflowers extracted the maximum of the contaminants after a vegetation period of 24 weeks and thereby also reached the highest biomass. So the sunflowers should be sown only once a year and cultured over 24 weeks, since with this approach the highest amount of contaminants can be removed. The exceptional extraction behavior of $\mathrm{Th}$ and $\mathrm{U}$ is not understood yet and will be investigated further.

\section{Conclusion}

The time-series phytoremediation experiment showed that sunflowers have a time dependent extraction behavior for the investigated elements. The contents of the elements alone are not the appropriate parameters to determine the ideal moment to harvest the sunflowers. The total extracted masses of the elements have to be calculated instead. We found that after 24 weeks of growth the extracted amount of elements is highest, due to a higher biomass production, even if the content in this time decreases. Nevertheless this can only be stated for sunflower and should be investigated for other plants, which seem to be promising candidates for phytoremediation.

\section{Acknowledgements}

The authors thank HIGRADE for funding.

\section{References}

Grawunder A, Lonschinki M, Merten D, Büchel G. Distribution and bonding of residual contamination in glacial sediments at the former uranium mining leaching heap of Gessen/Thuringia, Germany. Geochem 2009; S2:5-19.

Madejón P, Murillo JM, Maranón T, Cabrera F, Soriano MA. Trace element and nutrient accumulation in sunflower plants two years after Aznalcóllar mine spill. Sci Tot Environ 2007; 307: 239-257. 

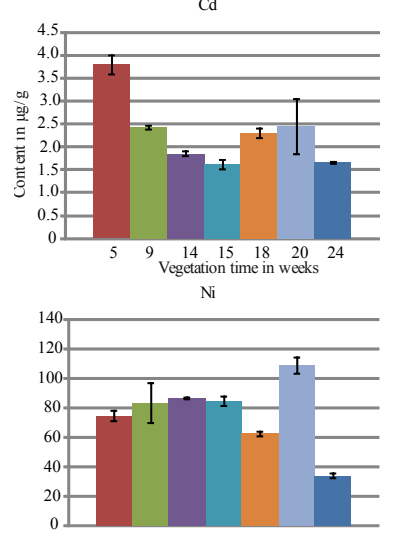

Co
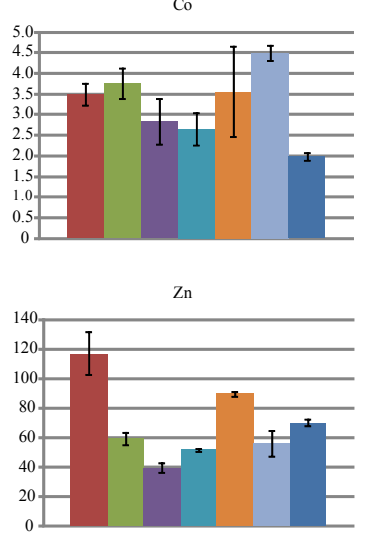

$\mathrm{Cr}$
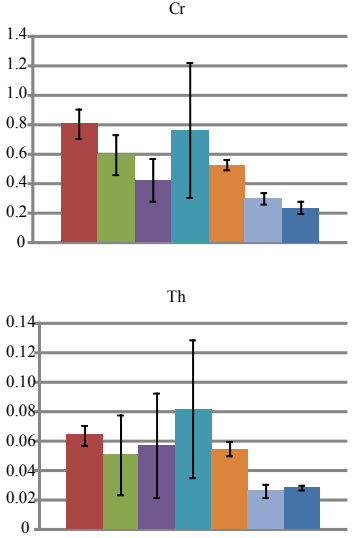
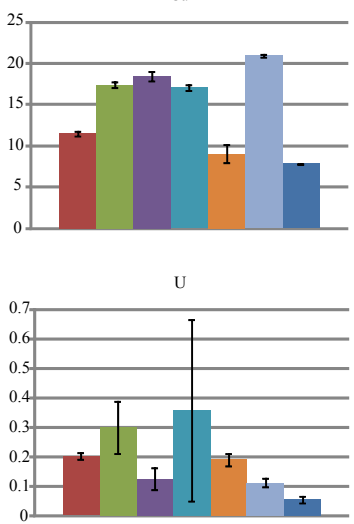

Fig 1.Concentration of the contaminants in the above-ground plant parts of sunflowers at different times of sampling (mean \pm confidence interval; two replicates)

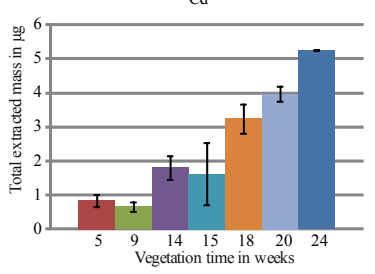

$\mathrm{Ni}$

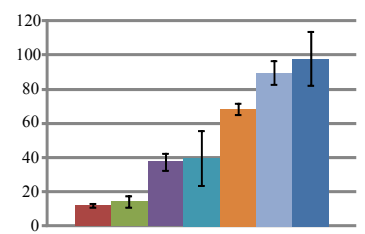

Co
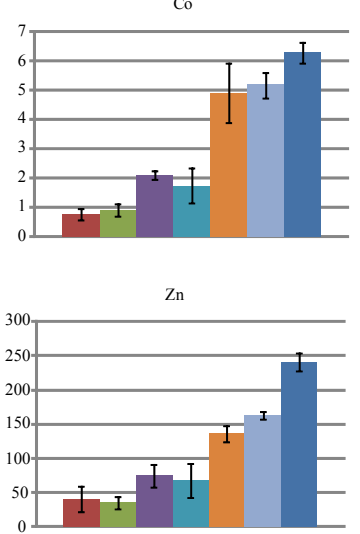

Cr
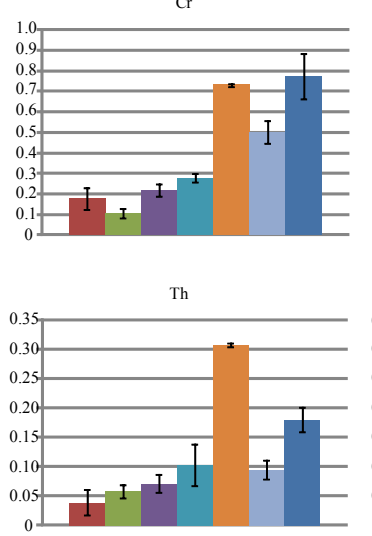

$\mathrm{Cu}$
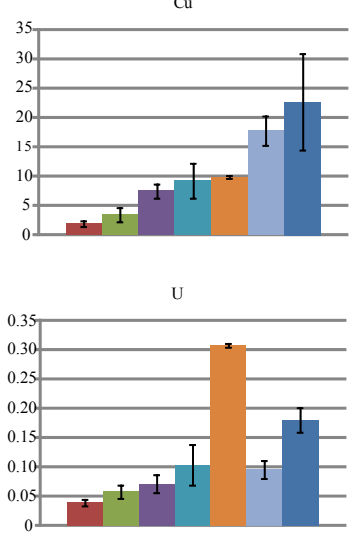

Fig. 2 Total extracted mass of the contaminants in the above-ground plant parts of sunflowers at different times of sampling (mean \pm confidence interval; two replicates).

Marchiol L, Fellet G, Perosa D, Zerbi G. Removal of metal by Sorghum bicolor and Helianthus annuus in a site polluted by industrial wastes: A feield experiment. Plant Physiol Bioch 2007; 45:379-387.

Piirto J. Eurostat Yearbook 2010. Luxembourg: Publications Office of the European Union; 2010.

Sabudak T, Seren G, Kaykioglu G, Dincer AR.
Determination of trace elements in soil and sundflower (Helianthus annuus L.) plant parts. Fresen Environ Bull 2007; 10: 1274-1278.

Singh A, Prasad SM. Reduction of heavy metal load in food chain: Technology assessment. Rev Environ Sci Biotechnol 2011; 10:199-214. 